\title{
Bridging the gap between RFID/EPC concepts, technological requirements and supply chain e-business processes
}

\section{Ygal Bendavid $^{1}$ and Luc Cassivi ${ }^{2}$}

Université du Québec A Montréal (UQAM), Department of Management of Technology, ${ }^{1}$ bendavid.ygal@uqam.ca,

${ }^{1}$ Académia RFID, Montéal, Ybendavid@rfidacademia.com

Received 9 August 2010; received in revised form 5 November 2010; accepted 15 November 2010

\begin{abstract}
Supply chain pressures have caused some firms to reexamine their processes. In doing so, firms are exploring emerging technology such as RFID to enable seamless exchange of information within their supply chain. While RFID promised to "revolutionize" the way business processes are managed today, the impact and benefits of the technology are still unclear and ambiguous concepts such as "intelligent products", "smart supply chains" or "the internet of things" are still creating confusion within potential adopters. In this paper an attempt is made to (i) clarify the ambiguity surrounding RFID vs. other AIDC and IOS technologies such as the EPC Network (ii) specify the technology readiness \& IT related requirements of actual and emerging applications, and (iii) propose a framework to highlight how the technology can be used to support RFID/EPC enabled ecommerce processes and support practitioners and academicians in assessing the impact of RFID on electronic supply chain business processes.
\end{abstract}

Key words: Supply Chain Management, Electronic Product Code, RFID, Electronic Commerce, Ubiquitous Commerce 


\section{Introduction}

Pressures to reduce supply chain costs, shrinking margins requirements for optimizing working capital, escalating service demand, increased risk exposure (security, environmental, financial instability), and the rise in business/multi channel complexity are some of the reasons why a number of firms have reexamined their supply chain management (SCM) processes in the last few years [78], [66].

In doing so, the focus on business improvement has moved from the single firm to consider the entire supply chain. In this context, emerging technologies such as RFID \& the EPC Network have been at the storefront to "revolutionize" the way business processes are now managed. The initial idea behind these technologies is to facilitate information capture, access and sharing, and to improve physical flow coordination, therefore allowing firms to move from a traditional supply chain model to a more integrated and synchronized supply chain model [9].

Since 2005, short after mandates to adopt the technology have been required by major prime contractors such as Wal-Mart and the US DOD, RFID technology has attracted the interest of the academic community. Since then, apart from the increasing number of papers being published on the subject, various special issues have contributed to explain technological and business aspects related to its adoption [19], [21], [25], [31], [36], [47], [52], [69], [71], [72] [79]. Among them, in its April 2008 issue (Volume 3, no. 1), Journal of Theoretical and Applied Electronic Commerce Research published a special issue on "RFID and Supply Chain Management" [18]. This paper is in line with this previous work and contributes to remove some remaining ambiguity from the subject, which is especially relevant since the literature on RFID applications in supply chains is still limited [67] .

In reality, despite the fact that RFID technology has been coined as the "next big thing in management" [84], and identified as "one of the ten greatest contributory technologies of the 21st century" [16], its early adoption has been plagued with numerous and complex issues such as technological uncertainties, lack of software applications, back end integration issues with Enterprise Information Systems (EIS), expensive software and services, data management challenges, lack of foreseeable benefits and unclear ROI for SCM applications, global standards issues and finally competition with established dominant designs (e.g. bar code) [12], [24], [77], [46], [83]. Although most of these challenges have been addressed, the RFID adoption process suffered from its early "over promising reputation". Accordingly, in 2009, Gartner research released its "technology Hype Cycle" [32], as a graphical way to track multiple technologies within an IT domain or technology portfolio. It is interesting to interpret how RFID followed a typical progression of an emerging technology, from over enthusiasm (somewhere in 2004/2005) through a period of disillusionment (somewhere in 2006/2008) to an understanding of the technology's relevance and role in a market or domain (i.e. presently). As some authors have already pointed out, the techno hype and the misunderstanding can be damaging to expectations; and RFID was no exception [60]! Fortunately, today, the availability of an increasing number of documented business cases contributes to facilitate the adoption process especially for "closed loop" RFID applications such as asset tracking or inventory management. More recently, surveys from ABI research [2] and RFID Journal [62] indicate that business process improvement is now "the number one driver for their adoption of RFID" (vs. cost cutting initiatives and mandatory compliance).

On the other hand, even though RFID in inventory and warehouse management seems better understood, still few companies have adopted RFID enabled functionalities within their core processes. In fact, despite efforts by major organizations such as the U.S. Department of Defense to encourage its suppliers to adopt RFID, only $5 \%$ of them have actually implemented the technology in their warehouses [62]. The situation is similar in the Consumer Product Goods (CPG) sector where only $2 \%$ of companies are now tagging their shipments.

Over the years, some RFID vendors (e.g. [3], [63]) practitioners (e.g. [10]) and academicians have proposed high level perspectives of RFID implementation guidelines [60], [39], [53] and taxonomy of currently available RFID technology and systems (e.g. [37], [34]). Although these frameworks are very pertinent, they lack a detailed view on HOW to asses the impact of the technology at the process level in terms of (i) business process changes, (ii) task management changes, (iii) IT configuration requirements, (iv) RFID technology requirements and (v) data flow integration.

This objective of the paper is hence twofold: (1) to provide a background for practitioners to clarify RFID technologies vs. other related concepts and technologies, and (2) to propose a framework that focuses on assessing the impacts of RFID/EPC technologies on B2B e-commerce supply chain processes.

The rest of the paper is organized as follows. First, the methodology and the research design are presented. Second, an attempt to clarify the ambiguity surrounding RFID vs. other AIDC (Automatic Identification and Data Capture) and IOS technologies such as the EPC Network is made. Concepts such as "intelligent products" or "smart supply chains" will be demystified. Third, a usable framework will be proposed in order to support practitioners and academicians in assessing the impact of RFID/EPC on B2B e-commerce supply chain processes. A case is presented to demonstrate how the framework can be used to identify where the technology may be best implemented to support advanced warehouse management functionalities. The paper concludes with implications and future research avenues. 


\section{Methodology \& Research Design}

As the main objective of the paper is to improve our understanding of RFID/EPC and analyze their impact in the context of supply chain activities, the research design is that of an exploratory research initiative adapted from Eisenhardt's framework [26]. Semi-structured interviews were first conducted between 2007 and 2009 with different series of professionals working in the field of RFID and supply chain management. The first series of interviews were carried out with RFID potential adopters and recent adopters, to assess their understanding of the technologies, identify and classify RFID elements (RFID technologies and concepts). These interviews focused on the following technical and business elements related to:

Inhibitors and facilitators to RFID adoption

- $\quad$ RFID within the AIDC portfolio

- $\quad$ RFID role within the EPC Global Network

- $\quad$ RFID role to enable supply chain emerging concepts (e.g. intelligent products, smart supply chain)

- $\quad$ RFID/EPC role to support and e-commerce emerging concepts (e.g. U-commerce)

- RFID/EPC enabled processes

Most of the interviews where carried out during various RFID conferences, workshops attended by the authors, as well as during seminars and professional training provided by the authors during the same period. This step helped the authors to summarize various preoccupations most commonly raised by actual and potential adopters (i.e. cross preoccupation/interrogation/ambiguity patterns), specify RFID important concepts and clearly identify the need to bridge an existing gap between realistic and potential RFID enabled supply chain possibilities. The analyses lead to a classification of (i) five different RFID technologies "level of complexity" from basic RFID physics to RFID role within the EPC Global Network (table 1 column i - technologies), and (ii) four main RFID/EPC concepts ranging from "intelligent objects" to "U-Commerce" (table 2 column i- concepts).

The next step was the validation by experts of the classification results. The definitions and IT related considerations were hence validated by the RFID experts, including RFID hardware vendors (i.e. tag and readers), RFID applications developers and RFID middleware and solution providers. Most of the face-to-face interviews where carried out during the 2007-2009 period, at different RFID events; for instance at RFID journal live conferences where the access to respondents was facilitated by the concentration of vendors at the exhibition center. With regards to clarifying the "EPC Network" concept, face-to-face meetings were organized with GS1/EPC Global representative (organizations in charge of developing/proposing/diffusing the standards for RFID/EPC in the supply chain). Furthermore, multiple conference calls and working sessions were conducted with GS1 (Canada) responsible of collaborative commerce and global standards initiatives. Data gathered from this step lead to elaborate on RFID/EPC definitions and technology readiness (table 1 column ii), and RFID/EPC concept and readiness (table 2 column ii). For example, in term of EPC Global Network, many questions were raised, namely: what was the real status of the network readiness? What electronic transactions are realistically possible to conduct today? Although some standards have been ratified, what are the major issues still remaining for the network to be fully operational? etc. A qualitative content analysis of the data gathered during this step also helped to formalize IT related requirements and identify more specific real life considerations in order to adopt RFID/EPC technology and "operationalize" envisioned concepts (table 1 and 2, column iii).

Data collected in the two previous steps also served to prepare and conduct specific laboratory experiments in a RFID laboratory. Within the front-end phase of innovation projects such as RFID projects, conducting laboratory experiments can be very useful for exploring emerging phenomenon such as RFID enabled e-supply chain models [6]. The laboratory approach tested the feasibility and pertinence of the concepts through the development, design and prototyping of simple RFID enabled supply chain processes (i.e. a proof and elaboration of concept).

For researchers, it constitutes a complementary environment to gather and analyze technical data, simulate RFID enabled processes, formalize their related technological requirements and respective technology readiness. It allows a better understanding of the real complexity behind the adoption of such emerging supply chain business models. Processes commonly used in supply chain processes were designed, tested and validated, namely: (i) automated receiving - using an RFID fixed portal and (ii) put away - using and mounted RFID reader on a pump truck and floor tags to identify locations, (iii) RFID assisted picking using a mounted RFID reader on a pump truck, and (iv) automated shipping - using RFID fixed portal. Additionally, a prototype of more advanced warehouse management functionalities such as RFID enabled labor tracking, or automated replenishment were also tested (figure 1).

Since the implementation of RFID technology is mostly driven by process changes, a Business Process Reengineering (BPR) approach was adopted. This was achieved by building information flowcharts, infrastructure and network blue prints, business process maps and using them to communicate with the laboratory team, 
composed of researchers, operation managers, software developers and RFID experts. The same types of documents were presented at various potential adopters for feed back (through seminars given at RFID journal Live, IT professional conferences and RFID specialized training), which pointed to the usefulness of using "graphical standards" to support the discovery process and refine our understanding of how managers could more easily move from an ill-defined concept (i.e. table 2, column i) to the identification of technological requirements (i.e. table 2, column iii), to designing a SCM e-business process (i.e. figure1).

\section{Smart Supply Chains: From Concept to Technological Requirements}

When exploring the ways managers evaluate RFID technology (i.e. speculate, forecast, and hypothesize) and participate in its adoption, "making sense" of RFID (i.e. understanding its value) is a complex process, especially for potential adopters often confused about RFID technology and prone to judgmental errors [55]. This raises an important aspect of RFID projects where adopters, with limited knowledge of the technology, are generally not geared for evaluating the multifaceted aspects of RFID deployments, and may not properly anticipate "Automation, Information, and Transformation effects" of the technology [5]. As Bendavid and Bourgault [6] p. 90 note in their study of an RFID project's front end phase, when considering the adoption of an emerging technology such as RFID, "potential users have vey few options to develop an understanding of the stakes, challenges and benefits outside the traditional working framework in which they rely: i.e. on consulting firms and solution providers".

Moreover, lacking a real understanding of the technology not only hampers the adoption process; it creates illusions where confused managers may develop unrealistic RFID enabled business and technological scenarios. Some authors have put forth the "myth and realities of RFID" [61], [33], suggesting that the "the state of the union between promise and practice" is not so evident. In line with [55] and [37], $\mathrm{Ng}$ [51] suggests that "(...) many potential adopters suffer from techno-ambiguity, they have preconceived ideas of what RFID will do for their company (...) the problem is not the technology, but what they were told it could do (...) to realize later that its not just about RFID technology, but about RFID middleware configuration, back end integration, Wireless Networks, business process changes, shop floor redesign, etc.". From this perspective, Michael et al. [49] point to the fact that RFID has a "great number of unfulfilled prospects", partially due to the fact that the "value proposition behind the technology" has not been widely recognized by the community of potential adopters. As the authors put it: "it has been marketed as a replacement technique for the barcode when the reality is that it has far greater capability than simply non-line-of-sight identification, towards decision-making in strategic management and reengineered business processes".

In order to grasp the realistic potential of RFID in the improvement of supply chain processes, along with assessing technical and managerial adoption problems, a comprehensive understanding of the technology and related concepts is required. To our knowledge this paper is the first formal contribution made to bridge the gap between RFID/EPC concepts, technological requirements and supply chain management processes. Table 1 is an attempt to (i) summarize actual \& emerging key RFID related concepts and technologies discussed in SCM literature and identified as important during our interviews, (ii) propose a definition and suggest a level of technology readiness, and (iii) clarify IT requirements for "grounding" those concepts with real life considerations.

RFID is first presented as a communication method using radio (electromagnetic) waves to communicate data (i.e. identification) by modulating and re-radiating (transmitting) a signal (table 1, row 1 (Table 1-1)). Without a proper understanding of the physics behind RFID, managers may see their judgment hindered - i.e. underestimating environmental factors or overestimating RFID potential, and consequently develop unrealistic supply chain scenarios.

In table 1-2, (i) RFID is presented as (ii) a set of different technologies (active, passive, semi-passive, and hybrid) categorized by their power source, frequency of operation and communication methods vs. a unique RFID technology, (iii) suggesting that each specific RFID technology is designed for particular applications. While many RFID technologies cohabit on the market, standards for data communication are still limited to passive technologies. Furthermore, there is no dominant design for active RFID solutions used to track high value products (e.g. yard management; intra walls asset tracking), where Ulra Wide Band-UWB, proprietary 433 Mhz., RFID/Infra Red- IR, and standards-based wireless networking solution such as WiFi or Zigbee, are competing. Fortunately, since 2003, performance improvement of UHF passive RFID technologies used in most SCM application has been exponential (novel anti-collision algorithms, improved communication protocols, hybrid antenna design, increased data capacity, dynamic authentication, ruggedized design, etc.) and interoperability between vendors is now possible (e.g. using an "Impinj" reader to read "Alien" tag). The main challenge for managers is now to properly understand each specific RFID technologies- i.e. realistic potential and limits, without which "it is impossible to intelligently discriminate between different technological scenarios and consequently develop viable RFID enabled supply chain solutions" [56].

In table 1-3, (i) RFID technology is presented as a system (ii) elaborated from multiple technological options between a set of hardware (i.e. tags, readers, antennas, printers, and ancillary devices) and software (i.e. proprietary pure play, development platform, open source or in-house custom solution), and (iii) suggesting that all solutions involve trade off analysis, in term of performance and cost. 
Table 1: RFID technologies and related IT requirements

\begin{tabular}{|c|c|c|}
\hline $\begin{array}{c}\text { (i) } \\
\text { Technologies }\end{array}$ & (ii) Definition \& technology readiness & $\begin{array}{c}\text { (iii) IT related requirements \& real life } \\
\text { considerations }\end{array}$ \\
\hline $\begin{array}{l}\text { (1) RFID } \\
\text { (Physics) }\end{array}$ & $\begin{array}{l}\text { Radio (electromagnetic) waves are at the heart of the } \\
\text { RFID system, they are used to communicate data (i.e. } \\
\text { identification) by modulating and re-radiating } \\
\text { (transmitting) a signal at a specific frequency. }\end{array}$ & $\begin{array}{l}\text { Transmitting and receiving device (i.e. a reader, } \\
\text { an antenna and a transponder) using inductive } \\
\text { or backscatter coupling (i.e. method of } \\
\text { communication). Active tags can use the existing } \\
\text { network (e.g. WiFi) to communicate }\end{array}$ \\
\hline $\begin{array}{ll}\text { (2) } & \text { RFID } \\
\text { technologies } \\
-\quad \text { Active } \\
-\quad \quad \text { Passive } \\
\text { - } \quad \text { Semi } \\
\quad \quad \text { passive } \\
\text { - } & \text { Hybrids }\end{array}$ & $\begin{array}{l}\text { RFID technologies, presently available in the market are } \\
\text { used to track objects with a minimum of human } \\
\text { intervention. Products are equipped with an RFID tag, } \\
\text { composed of an IC (chip) and an antenna (transmitter): } \\
\text { categorized by its power source and frequency of } \\
\text { operation. } \\
\text { - Passive: not equipped with a battery, various } \\
\text { applications: LF (e.g. automated payments), HF (e.g. } \\
\text { file/book management), UHF (e.g. warehouse, } \\
\text { logistic) } \\
\text { Active (UHF, Ghz -Wifi, UWB): equipped with } \\
\text { battery/transmitter for long range tracking (e.g. } \\
\text { asset/yard management). } \\
\text { Semi passive (UHF, Ghz): equipped with } \\
\text { battery/sensor for condition monitoring (e.g. Cold } \\
\text { chain management) } \\
\text { Hybrids: RFID tags including RFID+ other AIDC (e.g. } \\
\text { USID, IR, etc.) }\end{array}$ & $\begin{array}{l}\text { While many RFID technologies presently cohabit } \\
\text { on the market, standards for data } \\
\text { communication are still limited to passive } \\
\text { technologies (No dominant design yet for active } \\
\text { RFID). } \\
\text { Each Specific RFID technology is designed for } \\
\text { specific application and can be complementary. } \\
\text { For instance: } \\
\text { - Active RFID tags are designed to track high } \\
\text { value objects over a longer distance. } \\
\text { Requirement for RTLS software application. } \\
\text { Passive UHF tags are mostly used for } \\
\text { pallet/box tracking (i.e. SCM applications } \\
\text { when integrated with WMS/ERP software). } \\
\text { Hybrids tags for more "versatile" } \\
\text { applications (e.g. choke point functionality } \\
\text { for detection \& WiFi card for intra wall full } \\
\text { coverage asset tracking) }\end{array}$ \\
\hline $\begin{array}{l}\text { (3) RFID } \\
\text { System }\end{array}$ & $\begin{array}{l}\text { RFID System presently available in the market are } \\
\text { composed of : } \\
\text { Hardware: Tags (active, passive, semi passive), } \\
\text { readers (fixed, mobile handheld, forklift mounted), } \\
\text { antennas (dipole, linear polarized antenna, circular, } \\
\text { omni-directional, etc.), printers (fixed, mobile, print } \\
\text { and apply), ancillary devices (input devices -e.g. } \\
\text { photo eye and output/feed back devices - e.g. light } \\
\text { stack in a portal / divert gate on a conveyor) } \\
\text { Software: RFID Middleware of various type - i.e. } \\
\text { proprietary, "pure play", development platform, open } \\
\text { source, or in-house Custom Software } \\
\text { Communication Network: RFID systems belong to } \\
\text { WPAN. In order to enhance the range of } \\
\text { communication, other network connection is required } \\
\text { (e.g. warehouse WLAN, GPS, LBS). }\end{array}$ & $\begin{array}{l}\text { Today, very few companies offer a complete } \\
\text { RFID system for SCM applications. Operation } \\
\text { managers are faced with multiple options in the } \\
\text { design of an RFID system. Active tags providers } \\
\text { are more "solution oriented". } \\
\text { - Taxonomy of RFID (systems) [37], [34] } \\
\text { - Trade off analysis: performance vs. cost } \\
\text { - } \quad \text { Middleware configuration [50], [13] } \\
\text { - Back end system integration for value } \\
\text { added transactions [40]. } \\
\text { Adaptation on enterprise systems/data } \\
\text { architectures for RFID Transactions (e.g. } \\
\text { [15]) }\end{array}$ \\
\hline $\begin{array}{ll}\text { (4) } & \text { RFIDI } \\
\text { AIDC } & \end{array}$ & $\begin{array}{l}\text { RFID is a wireless Automatic identification and data } \\
\text { capture (AIDC) techno. AIDC are distinguished in two } \\
\text { groups presently available in the market: } \\
\text { - Biometrics, or feature extraction (e.g. finger print } \\
\text { facial/voice recognition) } \\
\text { - Data carrier technologies (optical storage, magnetic } \\
\text { storage and electronic storage technologies such as } \\
\text { RFID) [35] } \\
\text { Other AIDC are Infra Red (IR) or Ultra Sound } \\
\text { Identification (USID) }\end{array}$ & $\begin{array}{l}\text { AIDC technologies are complementary. All data } \\
\text { parent/child relationships could be managed on } \\
\text { a simple data base. For instance a shipment } \\
\text { tracking could use: } \\
\text { - } \quad \text { Active RFID tag a container Level, } \\
\text { - } \quad \text { Passive UHF RFID tag at pallet level (e.g. } \\
\text { EPC Number), } \\
\text { - Linear bar code for boxes ID (GTIN } \\
\text { Number), } \\
\text { 2D barcodes for Item level tracking (SGTIN } \\
\text { Number) }\end{array}$ \\
\hline $\begin{array}{l}\text { (5) RFID } \\
\text { within the } \\
\text { EPC Global } \\
\text { Network }\end{array}$ & $\begin{array}{l}\text { EPC Network: Electronic platform for secure exchange of } \\
\text { supply chain information [74]. The (forthcoming) } \\
\text { infrastructure will allow data sharing using standardized } \\
\text { EPC numbers to retrieve product information over the } \\
\text { internet [4] } \\
\text { - What physical objects were involved (i.e. EPC or } \\
\text { other IDentifier) } \\
\text { - When the event took place (i.e. timestamp) } \\
\text { Where the event took place (i.e. location identifier) } \\
\text { Why that business process step was being carried } \\
\text { out (i.e. operation) } \\
\text { Although some standards have been ratified [28], major } \\
\text { issues still remain for the network authorization to data } \\
\text { access/sharing \& authentication of senders and receivers } \\
\text { of data [64], [22]. Results from Pilot conducted in } 2008 \\
\text { have demonstrated how the standard could be used to } \\
\text { enable real-time cargo visibility [27]. }\end{array}$ & $\begin{array}{l}\text { This is a multi layer network including: } \\
\text { - } \quad \text { Infrastructure platform for data capture: i.e. } \\
\text { RFID tags \& readers } \\
\text { - Electronic platform for data translation: } \\
\text { EPCIS Middleware } \\
\text { - Electronic platform for data exchange: } \\
\text { o ONS to direct EPC queries (input) to the } \\
\text { location/URL (output) where metadata } \\
\text { and services associated with the EPC } \\
\text { can be accessed by authorized users. } \\
\text { o Discovery service for authentication of } \\
\text { users and authorization to data access } \\
\text { (1) Data standards related to object identity } \\
\text { (EPC), (2) Interface standards related to } \\
\text { EPC data capture (e.g. air interface } \\
\text { protocols), (3) Interface specifications } \\
\text { standard for exchanging EPC related data } \\
\text { between supply chain partners (EPCIS, } \\
\text { ONS, ALE, DSS) }\end{array}$ \\
\hline
\end{tabular}


When looking at technology readiness in SCM context, one notes that most of the companies are more "RFID component" providers (e.g. Alien and Impinj tags and readers) than RFID system providers (i.e. offering a complete RFID system for SCM applications). With the exceptions of a few companies such as Tsinghua Tongfang Co, HighJump, Apptricity or 4uLogistics, potential adopters are faced with numerous options in order to solve their problems.

Conversely, active tags providers (e.g. Ekahau, Aeroscout, Awarepoint, Ubisense) are more "solution oriented" and provide a basic Real Time location Systems (RTLS) middleware platform. For instance, in healthcare sector, RTLS are used to locate (i.e. tracking technology), monitor (i.e. reporting tool) and measure (i.e. data analytics) the status and location of high-value equipment. Nonetheless for more advanced applications such workflow automation solutions, active tag providers often partner with "pure players", offering specialized solutions (e.g. Patient Care Technology systems, intelligent insites). Finally, whatever the selected type of middleware platform, namely: proprietary to your infrastructure (e.g. SAP AII), "pure play" (e.g. Shipcom wireless), development platform (e.g. Microsoft RFID Biztalk, IBM Websphere), open source (e.g. Fosstrak, Rifidi Edge Server), or in-house custom software, configuration, back end integration and network connection remains an important issue in most of RFID project [15], [50]. As mentioned by Tzeng et al. [75] p. 612 "The RFID system reaps its whole added-value when integrated into existing systems since the data processed by the middleware allows automated transactions to be performed".

Therefore, when designing a RFID solution, operation managers come across a first dilemma when faced against the identification, the assessment and selection of an appropriate RFID technology for their application. In addition, managers have to be prepared (a) to justify RFID marginal contribution vs. other AIDC, and (b) the tagging strategy related to the desired level of information granularity. In table 1-4, (i) RFID is presented as a wireless AIDC technology (ii) that can be distinguished between biometrics, or feature extraction and data carrier technologies [35], (iii) that are complementary when building a multi tagging solution. For instance, a shipment tracking process could be done using various layers of AIDC, namely an active RFID tag at the container level, a passive UHF RFID tag at the pallet level, a linear bar code for boxes ID, and finally a 2D barcode for item level tracking. All data parent/child relationships (i.e. RFID Electronic Product Code (EPC) numbers and Serialized Global Trade Identification Numbers (SGTIN)) can be managed on a database. This suggests that requirement analysis is necessary to properly answer various questions such as: "what" reading/writing distance is needed (i.e. related to investigated application/business process)? "Which" data is required (i.e. key information about each item)? "Where" are items identified in the processes? "How much" products (tags) will be read at a time? At "what" speed"? etc. Nonetheless, one of the most important questions, when designing an electronic business model, is "where" the data will reside and "how" it will be shared between supply chain members. This is where operation managers will have to decide between "data-on-tag concept" where the tag acts as a mobile decentralized data base- i.e. with requirements for tag data read and write capabilities vs. centralized "data-on-network concept" with network access requirements (i.e. separation of object and data) [23]. A hybrid solution can also be envisioned, for instance in the aerospace industry where "high Memory -i.e. up to 64 kilobytes" tags are now being introduced to store and share some information between aircraft manufacturers, parts suppliers, airlines and maintenance organizations [80]. Among the network options for sharing RFID related data (e.g. private network, electronic marketplaces), the EPC global Network envisioned since the early 2000 [68] is now more documented in the literature [74]. Confusion, however, remains when considering its technological infrastructure and related standards.

In Table 1-5, the EPCglobal Network is presented as an infrastructure by which trading partners can securely, capture, share and discover dynamic information (i.e. EPC/RFID related data about items as they move within and between facilities), using standardized EPC numbers and data transfer protocols. There are two main components of the EPC Global network. The first component is related to technological infrastructure, which includes the (i) RFID system (i.e. tags, readers, middleware) and (ii) an electronic platform for exchange of standardized EPC data; i.e. the network. Basically, exchanging EPC/RFID related data over the EPC network is not different from Electronic Data Interchange (EDI) using standard format. In fact it can be seen as an extension of EDI as the exchange of electronic business messaging will remain similar; while the data capture technique will be different. In line with this idea, the communication channels used to send EPC/RFID related messages can be done over various electronic platforms, including private network (i.e. trading partner-specific electronic communication link) or through a third-party Value Added Network (VAN). The challenge is to translate the data capture into a transaction before sending the resulting (standardized) information through the network.

The second component is related to:

1. Data standards related to object identity - i.e. tags data structure and translation,

2. Interface standards related to EPC data capture, including air interface protocol, reader interface protocol, network access controller protocols,

3. Interface specification standards related to data exchange including (a) Application Level Events (ALE) standards -i.e. interface through which clients may obtain filtered, consolidated EPC data from a variety of sources -i.e. EPC processing systems - i.e. a similar approach to open services interfaces to easily create and introduce new applications (b) EPC Information Services (EPCIS) standards, necessary for the storage, communication and dissemination of EPC data coming from the EPC Middleware or from the back end EIS, 
(c) Object Naming Service (ONS) standards to indicate how to direct EPC queries to the location where information associated with that EPC can be accessed by authorized users (i.e. discovery of data sources), and (d) Discovery Services Standard (DSS), which is a mechanism for securely locating all read events and information for a given EPC, regardless of the data owner and ensuring authorization to data access \& authentication of users.

Using EPCIS standards, enterprises are therefore in a position to record "events" triggered by capturing RFID tags ID (or other AIDC), and transform these "events" into information used by business applications. This is done by using four main parameters as inputs: information related to EPC IDentifier (What), time stamp of data capture (When), location identifier (Where), and business process step (Why) [4]. Some extensions that have been recently used in EPCIS pilots include other criteria such as "expiration date, batch number, and temperature". Unless more extensions are integrated, visibility into real life transactions will remain limited and ability for enterprise to effectively respond to changing business needs, and exploit ever improving RFID systems capabilities will remain limited, and the operationalisation of "smarter supply chains" will be delayed for a few years.

Contrary to a common belief, this electronic platform is not yet ready for use. Although some standards have been ratified, such as the EPCIS (April 2007) the ONS (May, 2008) or the ALE (March 2009), other standards are still in development (e.g. DSS) and a Core Business Vocabulary (CBV) to standardize data contained in EPCIS events is yet to come [28]. Encouraging results from pilots conducted since 2006 have demonstrated how the EPCIS standard could be used to enable real-time cargo visibility (movement, location and disposition of assets, goods and services) between global supply chain member, as well as to validate the use of both passive and active UHF RFID/EPC tags as well as the use of EPCIS with other AIDC such as two-dimensional bar code labels (e.g. [27]). Additionally, other standards specifically adapted for vertical industry supply chains are being developed by "industry action groups" (IAG). Still, today, major issues remain when considering "authentication" of senders and receivers of data and "authorization" to data access. Although commercial off-the-shelf hardware can be adapted to address security requirements resulting from the usage of a single tag for multiple companies remain a challenge (e.g. [64]). According to Dean [22] director of architecture standards at GS1 Canada, "the platform, as envisioned today shouldn't be available before at least 5 to 10 years".

Having clarified the sustaining technologies to RFID enabled supply chain, in table 2-1, (i) "Intelligent products" and derived concepts such as "talking inventories" or "autonomous pallets" are introduced, (ii) a definition is provided highlighting the multiple requirements for a product to become really "intelligent" and (iii) the underlying technological considerations where (a) products equipped with RFID tags (b) can be automatically be detected - i.e. with choke point events triggers (c) to start a communication process with a network of readers and antennas (d) using standardized data \& interfaces (e) before decision/action based on business rules configured in a middleware platform and integrated with back end system are taken.

While the concept is technically feasible, financial viability of "intelligent products" [82] applications are still limited to basic applications. For example, Custom Cupboards, a wood cabinet maker uses an RFID-driven production management system to track Work In Process (WIP) and to automatically guide production equipment. When materials arrive at a production station, an RFID tag applied to an "intelligent" wood product communicates automatically with the production equipment to identify the job order and automatically makes the cuts according to the job requirements, "without requiring operator intervention to set up the machine" [73]. Although such applications are interesting, developing and maintaining more complex RFID based applications is difficult because developers have to (a) anticipate and configure all relevant scenarios (use case) in the middleware, and (b) learn to manage various interfaces and protocols especially when using components and interactive module of the EPC Network [50]. Having discussed basic technological and conceptual aspects related to RFID \& the EPC Network, we introduce, in table 2-2, the (i) the so called "smart supply chain" concept [11], [58] that can be defined as (ii) a collection of "smart processes" automatically triggered to perform specific transactions such as automated receiving and shipping, real time cycle counting, assisted picking, etc. [8], [30]. Basically, (iii) "Smart supply chain", requirements are similar to those of "intelligent products" (table 2-1) relying on RFID systems and IOS such as the EPC Network. These requirements can be summarized as (a) an RFID system within each supply chain member's facility, (b) item level RFID tagged products with standardized data structure (i.e. EPC numbers), (c) standardized communication protocols within and between supply chain members (i.e. EPCIS), (d) capabilities to update back end systems in real time, (e) electronic Data Interchange (EDI)/ e-commerce technologies integration. Again, although the concept is technically feasible, financial viability for RFID adoption within the supply chain, standards issues and security concerns limit deployments. Today, at best, "smart supply chains" exist only to some extent, i.e. within very circumscribe processes, within very few enterprises, and essentially within "close loop" intra-enterprise applications.

Ultimately, all theses concept converge toward a broader concept envisioned in the early 90's known as Ubiquitous commerce (U-commerce) [81]), which can be considered as an evolution of e-commerce. U-Commerce represents a new paradigm in the sense that "computation and (wireless) communication capability is embedded into objects, location and even people, making it possible to interact freely with digital resources at any time, and every where" [65]. Based on this idea and on the potentiality of RFID and the EPC global network, the "Internet of things" was envisioned at the initial phase RFID adoption process (i.e. in the early 2000s). 
Table 2: RFID derived concepts and related IT requirements

\begin{tabular}{|c|c|c|}
\hline (i) Concepts & (ii) Definition \& concept readiness & $\begin{array}{l}\text { (iii) IT related requirements \& real life } \\
\text { considerations }\end{array}$ \\
\hline $\begin{array}{l}\text { (1) } \\
\text { "Intelligent } \\
\text { products" } \\
\text { and related } \\
\text { concepts } \\
\text { such as } \\
\text { "Talking } \\
\text { inventories" } \\
\text { or } \\
\text { "Autonomous } \\
\text { pallets \& } \\
\text { boxes" }\end{array}$ & $\begin{array}{l}\text { Derived from the Object to object }(\mathrm{O} 2 \mathrm{O}) \text { communication } \\
\text { concept, an "intelligent product" features many requirements } \\
\text { [82]. } \\
\text { For instance: } \\
\text { - Possesses a unique identity } \\
\text { - Is capable of communicating effectively with its } \\
\text { - } \quad \text { Canvironment } \\
\text { - Deploin or store data about itself } \\
\text { - requirements etc. } \\
\text { Is capable of participating in or making decisions } \\
\text { relevant to its own destiny } \\
\text { Concept technically feasible but financial viability limits } \\
\text { deployments. E.g.: RFID-driven production management } \\
\text { system for WIP application (e.g. [73]), where an "intelligent } \\
\text { products" automatically communicate with production } \\
\text { equipment to "ask" for a specific job. }\end{array}$ & $\begin{array}{l}\text { There are multiple technical requirements for } \\
\text { products to become "intelligent" (e.g. a } \\
\text { configured RFID system). } \\
\text { - } \quad \text { Products equipped with RFID tags (data } \\
\text { carrier)/item level } \\
\text { - Automated "event notifications" to trigger } \\
\text { communication (e.g. choke point detection } \\
\text {-e.g. motion sensors/exciters or beaconing } \\
\text { tags to indicate their presence) } \\
\text { - Operational business intelligence: } \\
\text { business/decision rules configured in a } \\
\text { Middleware platform (e.g. if <event> then } \\
\quad \text { transaction> else <message>) for action } \\
\text { (transaction) } \\
\text { Network of readers and antennas for } \\
\text { transmitting / receiving } \\
\text { Back end system integration (e.g. with } \\
\text { existing ERP, WMS) } \\
\text { Standardized data \& interfaces (i.e. } \\
\text { common language) }\end{array}$ \\
\hline $\begin{array}{l}\text { (2) "smart } \\
\text { warehouse } \\
\text { "Smart } \\
\text { supply } \\
\text { chain", }\end{array}$ & $\begin{array}{l}\text { Self managed supply chain with automated synchronization } \\
\text { between the flow of products and the flow of information } \\
\text { [11], [58] } \\
\text { Can be seen as a collection of "smart processes" [8], [30] } \\
\text { within enterprises (e.g. Receive, Put away, Pick, Pack, Ship, } \\
\text { Cycle count, etc.) and the supply chain (Plan, source, Make, } \\
\text { Deliver, Return). } \\
\text { Concept technically feasible but adoption/deployment is } \\
\text { inhibited by financial viability, standards issues and security } \\
\text { concerns. Ability to update back end system in real time is } \\
\text { also an issue to "real time enterprise management". }\end{array}$ & 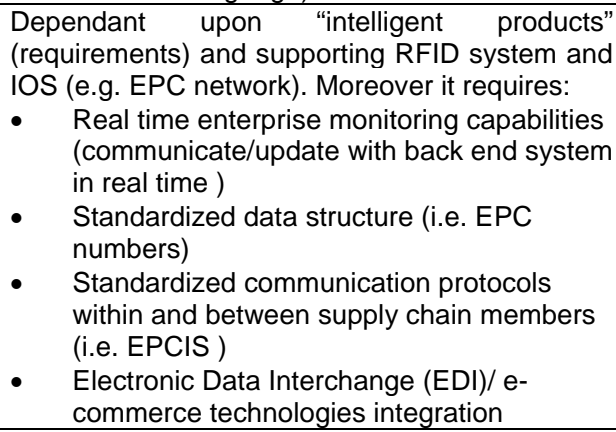 \\
\hline $\begin{array}{l}\text { (3) "Internet } \\
\text { of things" }\end{array}$ & $\begin{array}{l}\text { U-commerce, represents an evolution of e-commerce } \\
\text { leveraging on auto-ID and sensing technologies: } \\
\text { - U-Commerce where computation and (wireless) } \\
\text { communication capability is embedded into objects, } \\
\text { location and people, making it possible to interact } \\
\text { freely with digital resources at any time, and every } \\
\text { where [59], [65]. } \\
\text { - The "Internet of things" is derived from the concept of } \\
\text { "Ubiquitous computing" [81] in which computing } \\
\text { devices are considered integrated into everyday } \\
\text { objects to allow them to communicate and interact } \\
\text { autonomously and provide numerous services to their } \\
\text { users } \\
\text { Metaphor for "the universality of communication } \\
\text { processes, for the integration of any kind of digital data } \\
\text { and content, for the unique ID of real or virtual objects } \\
\text { and for architectures that provide the communicative }\end{array}$ & $\begin{array}{l}\text { Idem requirements than "Smart supply chain / } \\
\text { Smart warehouse". Moreover other requirements } \\
\text { for: } \\
\text { - Multi level tagging (objects/device/ } \\
\text { persons/locations) with RFID and other } \\
\text { AIDC technologies } \\
\text { - Sensors (e.g. temperature, air pressure, } \\
\text { humidity) } \\
\text { - Automated events to trigger data } \\
\text { communications / transactions: i.e. self ID } \\
\text { of interconnected and ubiquitous computing } \\
\text { objects/ devices } \\
\text { - Pervasive computing and networks } \\
\text { environments for device to device } \\
\text { communication } \\
\text { Indoor RTLS/Outdoor Geo-localization } \\
\text { technologies }\end{array}$ \\
\hline $\begin{array}{l}\text { (4) } \\
\text { "Ubiquitous } \\
\text { Commerce" }\end{array}$ & $\begin{array}{l}\text { glue among these components" [14] p. } 10 \\
\text { Related concepts: "silent commerce" [29]: execution of } \\
\text { business "transparent" transactions between electronic } \\
\text { devices- i.e. without human intervention nor customer } \\
\text { awareness. "Uberveillance" [48]:managing supply } \\
\text { chain visibility, velocity, and variability based on the } \\
\text { pervasive ability to "surveil" an item or person handling } \\
\text { an item, end-to-end, from the primary producer to the } \\
\text { end user (i.e. know the what, the where, the when, and } \\
\text { the condition of an object) } \\
\text { Still Conceptual for most applications. Ability to integrate } \\
\text { multiple heterogeneous systems and data/communication } \\
\text { standards are still an issue to adoption. Information security } \\
\text { and privacy are also important concerns. Many } \\
\text { developments to follow within the field of NFC (e.g. } \\
\text { convergence of NFC devices and far field devices) and } \\
\text { emerging e-commerce platforms based on the "cloud } \\
\text { computing" model. }\end{array}$ & $\begin{array}{l}\text { - Cameras and Web cams to record and } \\
\text { diffuse events, } \\
\text { Extended data/communications standards } \\
\text { structures (i.e. similar to GS1/EPC global } \\
\text { standards). For instance: extended EPCIS } \\
\text { standards for understanding more complex } \\
\text { data elements than the What, Where, } \\
\text { When, and Why events occurring in any } \\
\text { supply chain. }\end{array}$ \\
\hline
\end{tabular}


It is hence derived from the concept of "Ubiquitous computing" [59], [65], [81] in which computing devices are considered integrated into everyday objects (indistinguishable) to allow them to communicate and interact autonomously and provide numerous services to their users. The "Internet of things" is viewed as a "metaphor for the universality of communication processes, for the integration of any kind of digital data and content, for the unique identification of real or virtual objects and for architectures that provide the communicative glue among these components" [14] p 10. In this sense, RFID emerges as a powerful and disrupting Innovation [41], [43] which represents far more than a technological hype and has deep implications for managing supply chains. In fact, as discussed in table 1, RFID is part of a broader technological ecosystem which coevolves to open new possibilities in term of data accessibility and sharing through innovative electronic commerce platforms.

RFID holds much promise to close the gap between the physical world and the virtual world, facilitating coordination between product flow and information flow, since information can travel seamlessly with the RFID-enabled product or can be accessed in near real time through the EPC Global Network [23] [45].

Although Ubiquitous commerce applications are technically feasible within a controlled environment, this is still conceptual for most real life applications as barriers to adoption are numerous. For instance, in term of technology, while RFID technology dominant designs are clearer (e.g. UHF Class 1 Gen2 for supply chain applications, active WiFi RFID for indoor RTLS), the ability to integrate multiple heterogeneous intra/inter organizational systems and applications is still an important issue to adoption. More specifically, IT requirements to support these concepts are similar to those of "smart supply chain", where in this case, (i) tagging is required for any objects, locations and persons, (ii) using RFID and other AIDC technologies but also sensors to capture various parameters (e.g. temperature, humidity) (iii) the capture of automated events is needed to trigger data communications/transactions i.e. self identification/communication of interconnected and ubiquitous computing objects/ devices (iv) RFID enabled computing and networks environments must be pervasive for everywhere/anytime device to device communication (v) Indoor RTLS and outdoor geo-localization technologies have to be integrated to locate and track objects, etc. While many issues remain, it is interesting to follow the constant developments within the technological ecosystem to anticipate the developments of U-commerce RFID based concepts. For example, to name a few, the developments within the field of NFC (Near Field communication), the convergence of NFC devices and far field RFID devices, the development of RFID middleware and application platform, the emergence of e-commerce platforms based on the "cloud computing" models, are all building blocs contributing to the operationalisation of these concepts.

Nonetheless, information security (authentication and authorization) and personal privacy remain important and challenging aspects to resolve; basically, similar concerns than those addressed when envisioning the EPC global Network [14]. Finally, in term of standards, "tagging the world" will require extended standardized data structure (i.e. similar to GS1/EPC global standards) to permit a non ambiguous identification of any object/device/location/people and common communication language. For instance, extended EPCIS standards should be developed for understanding more complex data elements than the What, Where, When, and Why events occurring in today's supply chain.

\section{Building RFID Enabled E-Commerce Supply Chain Processes: Framework, Tools \& Methodologies}

When considering the adoption of an emerging technology such as RFID for improving e-commerce supply chain processes, operation managers and practitioners seek the best approach to initiate these multi-stakeholder multitechnology projects. This can be a "chaotic" exercise, as some authors [55] suggest that available models in the literature that look into how managers understand the "transition from strategic-to-operational problem-solving and from limited-to-complex "sensemaking and influencing" of RFID adoption" are not clear or conclusive. On the other hand, the literature, notably in IT, notes that RFID project share similar issues to business process reengineering (BPR) projects [6], [53] such as enterprise resource planning (ERP) and EDI/IOS implementations. Developing an understanding of the technical and managerial stakes, challenges and adoption issues, may be done using existing tools and frameworks, which can be derived from accessible operation consulting process (e.g. [17]). Differences may only exist in the nature of the problem analyzed and the analytical methods to be employed. Having agreed on the prerequisite to get operation managers "educated" on RFID/EPC systems, a more balanced relationship could be developed with consulting firms and solution providers, where managers could act as an active participant instead of relying on them during the research process.

"Knowledgeable" managers could then adapt and use existing tools to:

- Define the problems and opportunities (e.g. issue trees, root cause analysis, gap analysis),

- Gather data on technical issues (e.g. site survey, IT infrastructure evaluation, IS portfolio assessment, wireless network) and business issues (flow charts, process maps, work sampling),

- Analyze data (value chain analysis, business process analysis tools and methodologies, computer simulation, statistical control tools, work sampling),

- Quantify RFID impacts by building ROI analysis (e.g. decision trees, balance scorecards, SCM frameworks - SCOR) and, 
- Manage the front end phases of RFID projects (e.g. Proof of Concept-POC, pilot project, New Products Development-NPD tools)

- Manage RFID project (e.g. BPR approaches, ERP/IOS implementation methodologies, IT project management guidelines).

\subsection{E commerce Supply Chain Business Process Management}

Since the implementation of RFID technology is mostly driven by process changes, a Business Process Management (BPM) approach was adopted to support practitioners and academicians in their understanding of RFID/EPC potential of adopting emerging electronic supply chain models. As discussed in section 2 (methodology and research design), this choice is also supported by the feedback gathered by the authors from participants through seminars and specialized training given at professional conferences such as RFID journal Live since January 2007. This approach is also in line with Lambert's definition of SCM with its emphasis on business processes, integration, information flow and value added activities: "the integration of business processes from end user through original suppliers that provides products, services, and information that add value for customers" [42]

\subsection{Business Process Management for RFID in SCM}

Although various Business Process Modeling Languages (BPML), standards and software systems have proliferated over the last two decades [40]; and have given rise to some confusion, researchers and practitioners may wish to position their work within the BPM life cycle methods, techniques, and tools used to support the process design, enactment, management, and analysis of operational business processes [76]. Within the realm of RFID projects, the use of graphical standards to support Business Process Modeling provide the basis which unifies business requirements to IS/IT requirements, data structure, and related business and operational processes.

For instance, the Event-driven Process Chains (EdPCs) formalism [70] was selected to the design and analysis RFID enabled supply chain processes. It was selected because it represents a simple and accessible formalism to any organization stakeholder to improve their understanding of supply chain business and operational performance, i.e. "Who (employees) does what (activities/processes), in what sequence (workflow), what services are provided (value) and which software systems are used in the process (IT architecture)?" A relevant aspect of the EdPCs formalism is its use of "events" (i.e. Happening for dynamic entities occurring at a point in time - such as a pallet passing through a portal) that trigger a "function" (i.e. an activity which needs to be performed - such as activating the antennas a reading the tags) and the resulting sequence of events (i.e. processing the resulting transaction- such as verifying tags number against electronic Put Away Order-ePAO number); suggesting that a process can be seen as a chain of events and functions (i.e. Course as an ordered succession of happening parts) linked by condition Boolean Value Specification or logical connectors (i.e." "N" and, "V" or, "XOR" exclusive or). In addition, it is possible to assign responsibilities (i.e. employee) to a specific function, allocate a system, which is used to perform the function (e.g. ERP, RFID reader, middleware), indicate information inputs and outputs (e.g. RFID/EPC data) specify business rules (e.g. "if" tags correspond to the numbers on the e-picking order "then" accept, "else" reject) (e.g. figure 1).

Although a BPM approach is suggested to understand RFID/EPC high level impacts in SCM e-business processes, within the realm of this paper, we do not intend to recommend any specific "graphical standards" to support Business Process Modeling (BPM). In addition, operation managers and IT practitioners involved in RFID/EPC projects should understand that various BPM standards might be used at different phases of the project life cycle [40]. For instance, "graphical standards" such as the EdPCs BPM notation (BPMN) proposed in this paper are generally used as to address the ("as is"/ "to be") processes design. An example of RFID enabled ecommerce warehouse business processes is presented in figure 1. On the other hand "execution standards" such as Business Process Execution Language (BPEL) or "Interchange standards" such as XML Process Definition Language (or XPDL) would be used to model, configure and enact RFID enabled electronic business processes in vendors BPM System engines. If RFID/EPC projects are multi-stakeholder, multi-technology projects [6], the usage of standard language should not constitute another layer of difficulties, but rather be commonly agreed on, and used to convert abstract model and express them into supply chain e-business processes.

\subsection{RFID Enabled E-commerce Supply Chain Business Processes}

Since warehouse management issues are numerous (e.g. data capture and transaction errors, inaccurate products location and stock loss, incorrectly picked items), it is to no surprise that some of the actual literature on RFID focuses on warehouse management improvement, often related to basic functions such as receiving, picking, putting-away, shipping and cycle counting (e.g. [44], [57], [77]). Conversely, other areas of RFID opportunities in warehousing, which also offer great potential for improvement, have not been really investigated yet. For instance, the use of RFID to support more advanced functions such as labor tracking, task management, or warehouse advanced picking \& replenishing in order to get early visibility of products movements such as inbound returns. RFID Laboratory experiments were used to assess the feasibility of such emerging applications through the development, design and prototyping of simple RFID enabled processes/applications. 


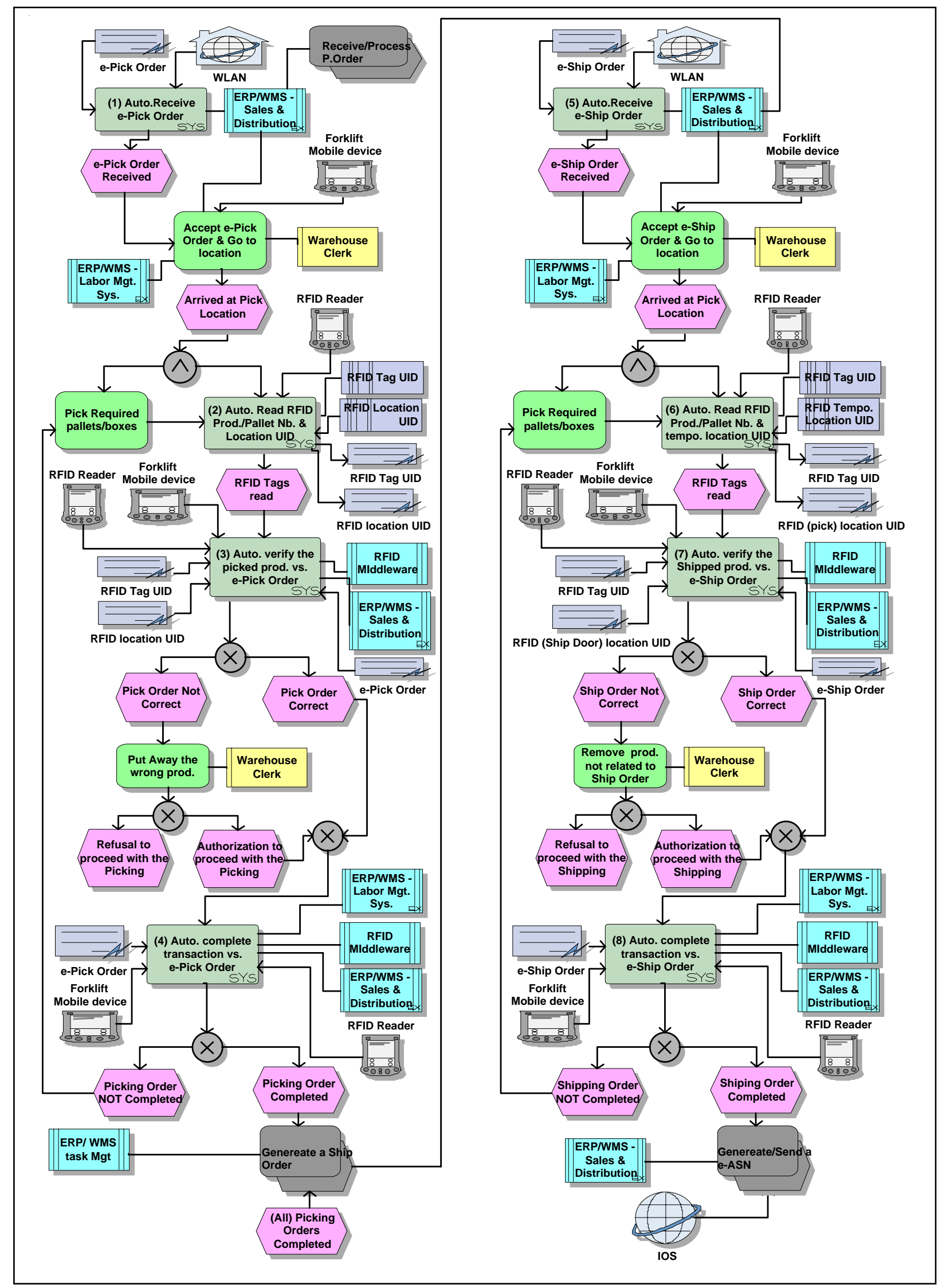

Figure 1: RFID enabled ecommerce warehouse business processes 
In figure 1, RFID enabled warehouse business processes are presented. For researchers, laboratory experiments permitted to gather and analyze technical data, formalize technological requirements related to simulated eSCM processes and realistically assess the technology readiness of the applications (i.e. available technology, level of difficulty to configure and deploy the application in a non controlled environment, etc.). In figure 1, the process starts as the warehouse clerk receives an e-Pick order (1). It is interesting to note that the order may have been generated at the client site as an event has triggered the transaction order (e.g. a product is being removed from a shelf). Nonetheless when designing such e-commerce supply chain business processes scenarios, issues and challenges and related technological requirements discussed in table 1 and 2 have to be kept in mind and eventually represented in the figure.

The e-doc generated by the ERP/WMS system is sent through a Wireless Local Area Network-WLAN on the forklift mobile device. Once the warehouse clerk accepts the task, and arrives at the pick location, RFID tag on the products and on the bin are automatically scanned (2), ensuring that the transaction is performed according to the order by verifying tag data output against ERP/WMS pick location (3).

Notice that a Labor Management System-LMS module allows tracking activities by warehouse worker in real time. At this stage, the RFID Middleware ensures the translation of events into business transactions. For this information to be shared within the network (IOS), the use of a data capture/ sharing standard such as the EPCIS should be used. It is interesting to note that as the picking is completed (4), a new task is automatically generated by the Task Management-TM module on the ERP/WMS, in this case, an e-ship order. The shipping process is then started (5) until completion (in 8) when an ASN (Advance Shipping Notice) is sent to the customer and before another task is generated.

Note that in this scenario the Ubicomp environment is restricted as (i) tagging is limited to employees; products, and locations; (ii) communication is limited to few device (i.e. forklift reader and mobile device), Intra/inter organizational network is limited to the warehouse proprietary LAN, and the company IOS, and finally (iv) application /systems interoperability are restricted to the company ERP/WMS/TMS/LMS.

It is important to understand that RFID/EPC does not replace any TMS, LMS or any other WMS module. The advantage of RFID is that it enables faster data capture, therefore increasing the ability to track activities by warehouse worker in real time and compare them against "labor standards". These enhanced capabilities enabled by increased shop floor visibility facilitate incentive-based pay programs and therefore constitute a tool to improve worker productivity. Moreover, as presented in figure 1, the technology can have cross benefits impact and improve the overall supply chain performance. For instance, companies can use the same RFID infrastructure to increase their orders put away/picked accuracy, shipped on time and complete orders, increase customer service performance and reduce inventory obsolescence (with real-time automated feedback on their transactions). Numerous benefits could be derived when RFID are integrated with LMS module. For instance, increasing visibility on operations by providing operation manager with an improved level of information granularity (labor/productivity tracking in real time), can improve shop floor control (i.e. how to manage floor activities), which in turn allows to better plan operations and related tasks. Conditionally, in order to adequately address the LM/TM events and automatically manage work assignment, underlying RFID systems and back-end integration need to be considered. For instance, LMS have to be integrated to Order Management Systems-OMSys, material handling systems, payroll systems, or more complete solution such as WMS and ERP (as presented here). Furthermore, mobile devices such as forklift mounted dashboard and RFID/barcode readers should be used. In the latest case, various options can be considered such as (i) active RFID tags mounted on forklifts for real time visibility of forklift location, or (ii) reader and antennas mounted on the forklift, reading tags on the floor for location based visibility. Passive vehicle access card could allow the matching between a forklift and employee.

Similarly, for the picking, which is one of the most labor intensive processes within a warehouse, multiple configurations can be envisioned. For instance, for cost concerns, mounting antennas on the shelves may not be a viable solution in a distribution center. RFID readers can therefore be mounted on the forklifts, on pump trucks, or be manually handheld. Any configuration has different impacts on warehouse performance. Again, Business requirements will drive the implementation strategy to support advanced picking functionalities (e.g. forward picking, batch picking, zone Picking) in order to reduce order picking/packing errors, reduce travel time, etc. In other cases, since RFID tagging at the item level can not be justified for all products, an alternative tagging approach would be to tag the container in which the items are stored instead of the item itself. Automated replenishment could be achieved by combining an RFID tagged bin with an "e-kanban" item replenishment system [7]. RFID in SCM constitutes another means to answer supply chain trends such as requirements for just-in-time (JIT) orders or direct-toconsumer orders (e.g. internet catalog) that are driving changes in "order profiles" and forcing managers to reconsider their picking methods. More generally, development of RFID technologies and the EPC global network are paving the way to concretize the vision of e-commerce where "smart" self managed supply chain will redefine the way we manage organization, but a requirement based realistic stance should prevent other unrealistic expectations by potential adopters. 


\section{Conclusion}

This paper presented RFID as another enabler of factory automation, as a means to enhance efficiency, effectiveness and reliability of industrial business and operational processes. As the challenge of gathering RFID based information is now controlled, the next step is to process more efficiently (i.e. manipulate, analyze, distribute) this information to achieve higher level of intra- and inter-organizational integration. This paper provides a basis for informing academicians and practitioners in the latest developments in RFID technologies and the EPC Network and should open a discourse on its realistic potential for the next few years, and its key role in the future development of U-commerce.

This paper leverages on previous attempts to understand RFID technologies and related area of research. It constitutes another building block in understanding "RFID technology, concepts and applications", and is a call for further work to be conducted by the academic community in this direction.

Although RFID represents an interesting area of opportunities to improve warehouse efficiency, more challenges are to come, as smaller orders (those with fewer pick lines and unit counts) are being treated more frequently in many industries and markets. In comparison to "full-case" or "pallet picking" operations, piece picking (i.e. individual units picked/packed into an outer carton/tote/container before shipping) typically has lower unit volume, lower revenue, and higher labor costs [1]. Until RFID tagging at item level isn't a commercially viable option, it will be difficult to foresee a clear contribution.

In term of theoretical contributions, this paper clarifies the ambiguity surrounding the various inter-twined concepts presented in the literature by grounding them with real life considerations (i.e. IT requirements and technology readiness) (table 1). As for practical contributions, this paper addresses some preoccupations raided by the scientific community, which points to the need for "appropriate models and methods to be developed for the design, development and implementation of RFID" [55], [54], [38], [20] in order to help managers understand why and how to adopt this particular technology. It contributes in terms of (i) helping practitioners/ adopters in understanding realistic RFID requirements on supply chain processes and help managers to move from initial business/operation requirements (e.g. real time task management) to related IT requirements (i.e. RFID infrastructure and information flow integration), (ii) identifying how the technology can be used to support more advanced WM functions such as labor management and task management (figure 1), (iii) providing a means to propose, design, analyze and optimize RFID enabled e-commerce supply chain scenarios, which is how the technology can contribute to an overall solution (figure 1).

\section{Acknowledgments}

The authors would like to thank the reviewers for their very useful comments which greatly helped in revising the paper.

\section{References}

[1] Aberdeen. (2008, June). Labor management for an agile warehouse. Aberdeen research group, Boston, MA. [Online]. Available: http://www.aberdeen.com/aberdeen-library/5271/Al-labor-management.aspx.

[2] $\mathrm{ABI}$ research. (2009). RFID End User Survey, ABI Research, New York, NY: [Online]. Available: http://www.abiresearch.com/research/1003626.

[3] Alien Technology. (2007, September). Common RFID implementation issues: 10 considerations for deployment, $\begin{array}{llll}\text { Alien } & \text { Technology, CA. } & \text { Aonline]. }\end{array}$ http://www.alientechnology.com/docs/WP RFID Implement issues.pdf.

[4] G. Asher, G. Morgan, R. Swan, and K. Traub (2007, April). EPCIS FAQ, EPC Global, [Online]. Available: http://www.epcglobalinc.org/standards/epcis.

[5] H. Baars, D. Gille, and J.Struker, Evaluation of RFID applications for logistics: a framework for identifying, forecasting and assessing benefits, European Journal of Information Systems, vol. 18, no. 6, pp. 578-591, 2009.

[6] Y. Bendavid and M. Bourgault, A university-based living lab for managing the front-end phase of innovation: The case of RFID implementation, International Journal of Project Organisation \& Management, vol. 2, no. 1, pp. 84108, 2010.

[7] Y. Bendavid, H. Boeck, and R. Philippe, Redesigning the replenishment process of medical supplies in hospitals with RFID, Business Process Management Journal, vol. 16, no. 6, pp.991-1013, 2010.

[8] Y. Bendavid, RFID Enabled B2B E-Commerce Technologies and applications in Encyclopedia of E-Business Development and Management in the Global Economy, (In Lee ed.), Chapter 129, Volume III, IGI Global, 2010, pp. 1284-1295.

[9] Y. Bendavid, E. Lefebvre, L.A. Lefebvre, and S. Fosso Wamba, Key performance Indicators for the evaluation of RFID enabled B-to-B eCommerce applications: the case of a five-layer supply chain. Information System and EBusiness Management Journal, vol. 7, no. 1, pp. 1-20, 2009.

[10] M. Bhuptani and S. Moradpour, RFID field guide: deploying RFID systems. NJ: Prentice Hall, 2005. 
[11] C. Bornhovd, T. Lin, S. Haller, and J. Schaper, Integrating smart items with business processes, an experience report, in Proceedings of the 38th Annual Hawaii International Conference on System Sciences (HICSS '05), Big Island, Hawaii, 2005, pp. 227c.

[12] I. Bose and C. Y. Lam, Facing the challenges of RFID data management, International Journal of Information Systems and Supply Chain Management, vol. 1, no. 4, pp. 1-19, 2008.

[13] California Software Labs. (2007, May). Light weight Framework for RFID Applications [Online]. Available: http://www.calsoftlabs.com/downloads/W rfid-applications.pdf.

[14] CASAGRAS/Coordination and Support Action for Global RFID-related Activities and Standardization (2008, http://www.rfidglobal.eu/userfiles/documents/CASAGRAS\%20Report.pdf.

[15] S. Chalasani and R. V. Boppana, Data architectures for RFID transactions, IEEE Transactions on Industrial Informatics, vol. 3, no. 3, pp. 246-259, 2007.

[16] C. Chao, J. Yang, and W. Jen, Determining technology trends and forecasts of RFID by a historical review and bibliometric analysis from 1991 to 2005, Technovation, vol. 27, no. 5, pp. 268-279, 2007.

[17] R. B. Chase, F. R. Jaccobs, and N. J. Aquilano, Operation Management For Competitive Advantage (11 ${ }^{\text {th }}$. Ed.), New York, NY: Mc Graw Hill, 2006.

[18] T. Coltman, R. Gadh, and K. Michael, Guest Editors' Introduction RFID and supply chain management: Introduction to the special issue, Journal of Theoretical and Applied E. Commerce Research, vol. 3, no. 1, pp. III-VII, 2008.

[19] D. Crawford, Editorial pointers, special issue: RFID. Communications of the ACM, vol. 48, no. 9, pp. 5, 2005.

[20] J. Curtin, R. J. Kauffman, and F. J. Riggins, Making the most out of RFID technology: A research agenda for the study of the adoption, usage and impact of RFID, Information Technology and Management, vol. 8, no. 2, pp. 87-110, 2007.

[21] F. F. Dai, C. E. Stroud and J. B. Zhang, Editorial to special section on industrial implementation of RFID systems, IEEE transactions on industrial electronics, vol. 56, no. 7, pp. 2295-2298, 2009.

[22] K. Dean, GS1 Canada, Toronto, ON, private communication on EPC/RFID in Heathcare, October 2009.

[23] T. Diekmann, A. Melski, and M .Schumann, Data-on-network vs. data-on-tag: managing data in complex RFID environments, in Proceedings of the 40th Annual Hawaii International Conference on System Sciences (HICSS'07), Big Island, Hawaii, 2007, pp. 224a.

[24] M. Dortch, Where RFID meets ROI: Beyond supply chains, Aberdeen research group, Boston, MA, Research benchmark, 2008, November.

[25] A. Dutta and S. Whang, Radiofrequency Identification applications in private and public sector operations: Introduction to the special issue, Production and Operations Management Society, vol. 16, no. 5, pp. 523-524, 2007.

[26] K. M. Eisenhardt, Building theories from case study research framework, Academy of Management Review, vol. 14, no. 4, pp. 532-550, 1989.

[27] EPCGlobal. (2009, April). Transportation and Logistics Phase 3 Pilot Program, EPC Global \& GS1 [Online]. Available: http://www.epcglobalinc.org/about/media centre/news/TLS 3 Pilot Program Completion PR V11.pdf.

[28] EPCglobal. (2010). EPCglobal Standards Overview, EPC Global, [Online]. Available: http://www.epcglobalinc.org/standards.

[29] G. T. Ferguson, Have your objects call my objects, Harvard Business Review, vol. 80, no. 6, pp.138-143, 2002.

[30] S. Fosso Wamba, E. Lefebvre, Y. Bendavid, and L.A. Lefebvre, From AIDC to smart Business Processes, in RFID Handbook: Applications Technology, Security, and Privacy, (S. Ahson, \& M. llyas, Eds.) Boca Raton: FL, Taylor and Francis, CRC Press, 2008, pp. 279-294.

[31] R. G. Gadh, Roussos, K. Michael, G. Huang, S., Prabhu, and P. Chu, RFID - A unique radio innovation for the 21st Century, in Proceedings of the IEEE, 2010, pp. 1541-1542.

[32] Gartner. (2009, August). Gartner's 2009 Hype Cycle, Gartner research, Stamford, CT. [Online]. Available: http://www.gartner.com/it/page.jsp?id=1124212.

[33] B. Hardgrave and R. Miller, The myths and realities of RFID, Journal of Global Logistics \& Supply Chain Management, vol. 1, no. 1, pp. 1-16, 2006.

[34] T. Hassan and S. Chatterjee, A Taxonomy for RFID, in Proceedings of the 39th Annual Hawaii International Conference on System Sciences, Kauai, Hawaii, 2006, pp. 184b.

[35] S. Hodgson, F. Nabhani, and S. Zarei, AIDC feasibility within a manufacturing SME, Assembly Automation, vol. 30, no. 2, pp. 109-116, 2010

[36] G. Q. Huang, P. K. Wright, A. Molina, and P. G. Ranky, Editorial on special issue: RFID \& wireless manufacturing, International Journal of Computer Integrated Manufacturing, vol. 22, no. 7, pp. 577-578, 2009.

[37] X. Huang, S. S. Le, and D. Sharma, A taxonomy for RFID systems, in Proceedings of IEEE International Conference on Signal Processing and Communication Systems, Gold Coast, Australia, 2007, pp. 1-8.

[38] Z. Irani, A. Gunasekaran, and Y. K. Dwivedi, RFID: research trends and framework, International Journal of Production Research, vol. 48, no. 9, pp. 2485-2511, 2010.

[39] E. Jones and C. A. Chung, RFID in logistics: a practical introduction, FL: CRC Press, 2008.

[40] R. K. I. Ko, S. S. G. Lee, and E. W. Lee, Business process management standards a survey, Business Process Management Journal, vol. 15, no. 5, pp. 744-791, 2009.

[41] V. Krotov and I. Junglas, RFID as a disruptive innovation, Journal of Theoretical and Applied Electronic Commerce Research, vol. 3, no. 2, pp. 44-59, 2008. 
[42] D. Lambert, Supply Chain Management, Process, Partnership, Performance (3 ${ }^{\text {rd }}$ ed.), Sarasota: FL, Supply chain management institute, 2008.

[43] E. Lefebvre, Y. Bendavid, and L.A. Lefebvre, Open innovation strategies in shaping technological progress: the case of RFID, paper presented at the 3rd European Conference on Management of Technology (EUROMOT), Nice, France, 2008, [Online]. Available: http://webintec.ceram.fr/euromot2008/conftool/uploads/438/1Lefebre et al Euromot FINAL 200805 06.doc.

[44] L. A. Lefebvre, É. Lefebvre, Y. Bendavid, S. Fosso Wamba, and H. Boeck, The potential of RFID in warehousing Activities in a retail industry supply chain, Journal on Chain and Network Science, vol. 5, no. 2, pp. 101-111, 2005.

[45] J. M. Leimeister, U. Knebel, and H. Krcmar 2007. RFID as enabler for the boundless real-time organisation: empirical insights from Germany, International Journal of Networking and Virtual Organisations, vol. 4, no. 1, pp. 45-64, 2007.

[46] S. Li, J. K. Visich, B. M. Khumawala, and C. Zhang, RFID technology: applications, technical challenges and strategies, Sensor Review, vol. 26, no. 3, pp. 193-202, 2006.

[47] M. Madni, H. P. D. Chalasani, and R. V. Boppana, Guest Editor's Introduction: RFID technology: opportunities and challenges, IEEE Systems Journal, vol. 1, no. 2, pp. 78-81, 2007.

[48] K.Michael and M. G. Michael, Innovative Automatic Identification and Location Based Services: from Bar Codes to Chip Implants, Hershey: IGI Global, 2009.

[49] K. Michael, G. Roussos, G. Q. Huang, A. Chattopadhyay, R. Gadh, B. S. Prabhu, and P. Chu, Planetary-scale RFID services in an age of uberveillance, in Proceedings of the IEEE, vol. 98, no. 9, pp. 1-9, 2010.

[50] T. Nam and K. Yeom, Business-aware framework for supporting RFID-enabled applications in EPC Network, Journal of Network and Computer Applications, In Press, Corrected Proof, Available online 20 May 2010.

[51] E. Ng, Building an RFID Portal, communication presented at RFID Journal Live RFID Journal preconference seminar, Orlando, FL, April 14, 2010.

[52] E. W. T. Ngai and F. Riggins, Editorial: RFID: technology, applications, and impact on business operations. International Journal of Production Economics, vol. 112, no. 2, pp. 507-509, 2008.

[53] E. W. T. Ngai, C. K. M. To, K. L. Moon, L. K. Chan, P. K. W. Yeung, and C. M. Lee. RFID systems implementation: a comprehensive framework and a case study, International Journal of Production Research, vol. 48, no. 9, pp. 2583-2612, 2010.

[54] E. W. T. Ngai, K. L. Moon, F. J. Riggins, and C. Yi, RFID research: An academic literature review (1995-2005) and future research directions, International Journal of Production Economics, vol. 112, no. 2, pp. 510-520, 2008.

[55] R. F. Otondo, A. W. Pearson, R. A. Pearson, J. C. Shaw, and J. P. Shim, Managerial problem-solving in the adoption of RFID Technologies, European Journal of Information Systems, vol. 18, no. 6, pp. 553-569, 2009.

[56] A. Palermo, What, where, when \& how to use RFID technology in the pharma supply chain, presented at the Annual Conference of Interphex, New York, April 20-22, 2010.

[57] T. Poon, K. Choy, H. Chow, H. Lau, F. Chan, and K. Ho, A RFID case-based logistics resource management system for managing order-picking operations in warehouses, Expert Systems with Applications, vol. 36, no. 4, pp. 8277-8301, 2009.

[58] K. C. Pramataris, G. I. Doukidis, and P. Kourouthanassis, Towards 'smarter' supply and demand-chain collaboration practices enabled by RFID technology, in Consumer Driven Electronic Transformation G.J. Doukidis and A. P. Vrechopoulos, Ed. Berlin: Springer, 2005, pp. 241-256.

[59] D. C. Ranasinghe, K. S Leong, D. Engels, and P. H. Cole, A Distributed Architecture for a Ubiquitous Item Identification Network, in proceedings of the Workshop on Smart Object Systems (2005, September), [Online]. Available: http://ubicomp.lancs.ac.uk/workshops/sobs05/papers/15\%20-\%20Ranasinghe.\%20Damith.pdf.

[60] P. M. Reyes and P. Jaska, Is RFID right for your organization or application?, Management Research News, vol. 30, no. 8, pp. 570-580, 2007.

[61] P. M. Reyes, G. V. Frazier, E. L. Prater, and A. R. Cannon, RFID: The state of the union between promise and practice, International Journal of Integrated Supply Management, vol. 3, no. 2, pp. 192-206, 2007.

[62] RFID journal. (2009, February). RFID Journal survey: companies reevaluate RFID deployments. [Online]. Available: http://www.rfidjournal.com/article/purchase/4591.

[63] Rockwell Automation. (2004, October). RFID in Manufacturing: A practical guide. Rockwell Automation, Milwaukee, WI. [Online]. Available: http://www.rockwellautomation.com/solutions/rfid/get/rfidwhite.pdf.

[64] M. Rossberg, M. Henseler, and G. Schaefer, Credential management for automatic identification solutions in supply chain management, IEEE Transactions on Industrial Informatics, vol. 4, no. 4, pp. 303-314, 2008.

[65] G. Roussos, Ubiquitous and Pervasive Commerce, New Frontiers for Electronic Business, Springer-Verlag London, 2006.

[66] V. Sadlovska and N. Vishwanata, Integrated demand Supply Network, five steps to gaining visibility and control, Aberdeen research group, Boston, MA, Research benchmark, 2009, March.

[67] A. Sarac, N. Absi, and S. Dauzère-Pérès, A literature review on the impact of RFID technologies on supply chain Management, International Journal of Production Economics, vol. 128, no. 1, pp. 77-95, 2010.

[68] S. Sarma, D. L. Brock, and K. Ashton, The networked physical world. proposals for engineering the next generation of computing. Auto-ID Center White Paper MIT-AUTOID-WH001, 1999.

[69] S. Sharma, M. H. Mickle, D. Mc. Farlane, P. Cole, and D.W. Engels, Editorial: special section on RFID, IEEE Transactions on Automation Science and Engineering, vol. 6, no. 1, pp. 1-3, 2009.

[70] A. W. Sheer, ARIS-Business Process Modelling (3rd ed.), Berlin, GE: Springer, 1999.

[71] M. Sheng, S. Zeadally, K. Mitrokotsa, and Z. Maamar, RFID technologies, systems and applications, Journal of Network and Computer Application, 2011, to appear. 
[72] Q. Z. Sheng, S. Zeadally, Z. Luo, J. Y. Cheung, and Z. Maamar, Advances in RFID technology. Information System Frontiers, vol. 12, no. 5, 2010, pp. 1-3.

[73] C. Swedberg. (2008, January 2). Custom Cabinetmaker Deploying RFID to Track Production [Online]. Available: http://www.rfidjournal.com/article/articleview/3827/.

[74] F. Thiesse and F. Michahelles, An overview of EPC technology, Sensor Review, vol. 26, no. 2, pp. 101-105, 2006.

[75] S. F. Tzeng, W. H. Chen, and F. Y. Pai, Evaluating the business value of RFID: Evidence from five case studies, International Journal of Production Economics, vol. 112, no. 2, pp. 601-613, 2007.

[76] W. M. P. Van der Aalst and K. M. van Hee, Workflow Management: Models, Methods, and Systems, Cambridge, MA: MIT Press, 2004.

[77] B. S. Vijayaraman and B. A. Osyk, An empirical study of RFID implementation in the warehousing industry, The International Journal of Logistics Management, vol. 17, no. 1, pp. 6-20, 2006.

[78] N. Viswanathan, Process Collaboration in Multi-Enterprise Supply Chains, Aberdeen research group, Boston, MA, Research benchmark, 2008, August.

[79] L. Wang, Editorial on Special Issue on AIT-Driven manufacturing and management, International Journal of Manufacturing Technology and Management, vol. 21, no. 3/4, pp. 207, 2010.

[80] E. Wasserman, RFID finally ready for takeoff, RFID Journal, vol. 7, no. 2, pp. 23-29, 2010.

[81] M. Weiser, Ubiquitous computing, IEEE Computer, vol. 26, no. 10, pp. 71-72, 1993.

[82] A. C. Y. Wong, D. McFarlane, A. Ahmad Zaharudin, and V. Agarwal, The intelligent product driven supply chain, IEEE International Conference on Systems Man and Cybernetics, vol. 4, pp. 6-12, October 2002.

[83] N. C. Wu, M. A. Nystrom, T. R. Lin, and H. C. Yu, Challenges to global RFID adoption, Technovation, vol. 26, no. 12, pp. 1317-1323, 2006.

[84] D. C. Wyld, RFID 101: the next big thing for management, Management Research News, vol. 29, no. 4, pp. 154173, 2006. 